Aging Clin. Exp. Res. 12: 13-21, 2000

\title{
Prevention of recurrent hip fracture
}

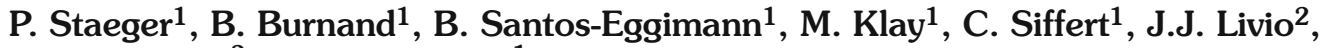 \\ P. Burckhardt ${ }^{3}$, and F. Paccaud ${ }^{1}$ \\ ${ }^{1}$ Institut Universitaire de Médecine Sociale et Préventive, ${ }^{2}$ Service d'Orthopédie et de Traumatologie, Centre \\ Hospitalier Universitaire Vaudois, ${ }^{3}$ Département de Médecine Interne, Centre Hospitalier Universitaire \\ Vaudois, Lausanne, Switzerland
}

ABSTRACT. Our objective was to describe the interventions aimed at preventing a recurrent hip fracture, and other injurious falls, which were provided during hospitalization for a first hip fracture and during the two following years. A secondary objective was to study some potential determinants of these preventive interventions. The design of the study was an observational, two-year followup of patients hospitalized for a first hip fracture at the University Hospital of Lausanne, Switzerland. The participants were 163 patients (median age 82 years, 83\% women) hospitalized in 1991 for a first hip fracture, among 263 consecutively admitted patients (84 did not meet inclusion criteria, e.g., age $>50$, no cancer, no high energy trauma, and 16 refused to participate). Preventive interventions included: medical investigations performed during the first hospitalization and aimed at revealing modifiable pathologies that raise the risk of injurious falls; use of medications acting on the risk of falls and fractures; preventive recommendations given by medical staff; suppression of environmental hazards; and use of home assistance services. The information was obtained from a baseline questionnaire, the medical record filled during the index hospitalization, and an interview conducted 2 years after the fracture. Potential predictors of the use of preventive interventions were: age; gender; destination after discharge from hospital; comorbidity; cognitive functioning; and activities of daily living. Bi- and multivariate associations between the preventive interventions and the potential predictors were measured. Inhospital investigations to rule out medical pathologies raising the risk of fracture were performed in only 20 patients (12\%). Drugs raising the risk of falls were reduced in only 17 patients (16\%). Preventive procedures not requiring active collaboration by the patient (e.g., modifications of the environment) were applied in 68 patients (42\%), and home assistance was provided to 67 patients $(85 \%$ of the patients living at home). Bivariate analyses indicated that prevention was less often provided to patients in poor general conditions, but no ascertainment of this association was found in multivariate analyses. In conclusion, this study indicates that, in the study setting, measures aimed at preventing recurrent falls and injuries were rarely provided to patients hospitalized for a first hip fracture at the time of the study. Tertiary prevention could be improved if a comprehensive geriatric assessment were systematically provided to the elderly patient hospitalized for a first hip fracture, and passive preventive measures implemented.

(Aging Clin. Exp. Res. 12: 13-21, 2000)

${ }^{\circ} 2000$, Editrice Kurtis

\section{INTRODUCTION}

Hip fracture is a major public health problem because of its high occurrence rate, and its heavy social, economic and human consequences. Between 1986 and 1991, the mean annual incidence for 100 000 people older than 20 years in the Canton of Vaud, Switzerland was 241 and 84 among women and men (1), respectively. This high rate is close to what is observed in other industrialized countries (2). A 10 to $20 \%$ excess mortality at 1 year has been observed after a hip fracture $(3,4)$. Moreover, 15 to $25 \%$ of the patients will loose their autonomy during the first year following the fracture $(4,5)$, which leads to an important use of home assistance ( 25 to $35 \%$ )

Key words: Falls, geriatric assessment, psychotropics, tertiary prevention.

Correspondence: B. Burnand, M.D., IUMSP, Bugnon 17, CH-1005 Lausanne, Switzerland.

E-mail: Bernard.Burnand@inst.hospvd.ch

Received December 9, 1998; accepted in revised form October 15, 1999.

Aging Clin. Exp. Res., Vol. 12, No. 113 
and institutionalizations (15 to 25\%) (6) with a heavy impact on health costs. The global estimation was about 8 billion US\$ in the USA in 1995. Because of the steady aging of populations in most industrialized countries, incidence and costs could double in 2040 (7).

Successful primary preventive interventions on hip fracture will therefore be extremely valuable $(8,9)$. However, tertiary prevention should not be overlooked, because recurrence of hip fracture is not rare. Indeed, 5 to $10 \%$ of all hip fractures are recurrences, and the risk of experiencing a second fracture is $15 / 1000$ person-years in men, and 22/1000 person-years in women $(8,10)$. Prevention of recurrence is essentially similar to primary prevention (8). However, how and how often prevention of the recurrence is practiced is largely unknown (10-13). The aim of this study, therefore, was to determine how frequently tertiary prevention of recurrent hip fracture and other injurious falls was provided, and to investigate if any personal characteristics of the patient were associated with preventive practices.

More than $90 \%$ of hip fractures are secondary to a fall $(14,15)$. Thirty percent of elderly people living in the community, and $60 \%$ of nursing home residents fall once or more during the year (16). Ten percent of falls lead to serious non-fatal injuries (9, 16 ), of which half are fractures, including $40 \%$ of hip fractures (17). In addition, $40 \%$ of institutionalizations are due to falls (18). Prevention programs include: reduction in global medication use $(7,19,20)$, particularly psychotropic and hypotensive agents (21$23)$; reduction in alcohol consumption $(19,22)$; improvement of environmental safety $(18,20,24,25)$; and increased home assistance, which could improve nutrition behavior and home safety. Other measures include: increase in strength and gait through physical training $(26,27)$; changes in dangerous behaviors like long lonely walks and climbing on chair or ladders (28); and use of proper shoes (29). Additional interventions consist of medical checking for pathologies which rise the risk of falling, such as hypotension (19, 30), musculo-skeletal problems $(9,25,31)$, proprioceptive or neurologic impairment $(25,30$, $31)$, dementia $(9,25,30)$, foot problems $(25)$ as well as visual $(9,30,31)$, auditory (9) or gait impairment $(9,25)$.

The other major risk factor for hip fracture in elderly people is osteoporosis (32-34). Some prophylactic therapies, like hormone replacement (35-37) as well as vitamin D or calcium supplements (38-40), are effective. In addition, treatments like calcitonin and biphosphonates (41) may reduce the risk of hip fracture, whereas the effect of fluoride is still contro- versial $(33,34,42)$. High-calcium intake during childhood, adolescence and beyond (43-45), appropriate sun exposure (46), physical training $(26,32,34)$, avoidance of smoking $(26,47)$, and reduction in steroid use (33) are other measures which help to reduce osteoporosis.

\section{SUBJECTS AND METHODS}

\section{Subjects}

In 1991, 263 patients were hospitalized at the University Hospital of Lausanne for a first hip fracture. One hundred and sixty-three patients were included in a study aimed at determining risk factors for hip fracture; 16 patients refused to participate, and 84 did not meet inclusion criteria: 50 years old or more, white race, first episode of hip fracture, no cancer with possible bone dissemination, no Paget disease, no pathological fracture, no high energy trauma. In 1993, these 163 patients were contacted for follow-up 2 years after the fracture in order to study mortality, morbidity, use of health and social services, and prevention of recurrence of falls and fractures. Every participant was seen at her/his place of living.

\section{Data}

Data were collected from the 1991 initial examination and, mainly, from the hospitalization medical records as well as the 1993 examination. The studied variables included demographic indicators, comorbidity, functional status, cognitive health measured by the short portable mental health questionnaire (SPMHQ) (48), autonomy (activities of daily living, place of residence), medication use, preventive interventions, and clinical signs. Because too few single preventive interventions were provided, an analysis of the determinants of their use was not possible; therefore, preventive interventions were grouped into 5 categories: medical investigations; prescription of drugs; counselling; environment modifications; and home assistance.

In this study, medical investigations were defined as examinations performed during hospitalization enabling the detection of conditions that increase the risk of fall recurrence. Investigations included in this category encompassed the visual, auditory, nervous and vestibular systems, cognitive function, cardiovascular and cerebrovascular systems, metabolism (including vitamin B12), locomotive apparatus, cervical status, and finally 'others'. A medical investigation was considered as performed whenever a consultation report, an exam result, or the specific exam request was found in the 1991 medical record. The 
category 'prescription of drugs' included drugs known to increase the risk of falling (psychoactive medications classified as sedatives, antidepressants or neuroleptics, as well as hypotensives) that were prescribed to the patients when they left hospital in 1991 and were used in 1993, and those affecting bone metabolism (calcium, vitamin $\mathrm{D}$ and hormone replacement therapy) used in 1991. Initiation of hormone replacement therapy was not recorded during hospitalization in 1991, nor at the 1993 followup. In addition, the total number of drugs used per day in 1993 was recorded, but not specifically regarding osteoporosis treatment; it was indeed not the primary goal of the follow-up.

'Counselling' included recommendations to alter behavior regarding physical exercise, and nutrition, as well as to consult for specific problems (e.g., ophthalmologist, podologist). No information was obtained from relatives of patients that eventually died during the follow-up regarding preventive recommendations. Environmental modifications to prevent fall recurrence by reducing home hazards consisted of improvements in lighting, reduction in bed height, placement of safety bars and anti-slip carpets (bathroom, kitchen), and suppression of obstacles (unfixed carpets, electrical cords, etc.) and other objects (ladder, etc.). Home assistance addressed preventive action by improving nutrition, avoiding activities that put patients at risk of falling, and by further reducing environmental hazards (housework, meals-on-wheels, nurse or auxiliary visits, etc.). In addition, physiotherapy provided after hospitalization, and the time spent outdoors in 1993 (a proxy for physical exercise and sun exposure which allows the synthesis of vitamin D) were considered.

For each category of preventive interventions, a score was calculated as a sum of possible points: 1 point for every intervention performed, and 0 point if the procedure was not conducted. This score was then reduced to a dichotomous variable: at least one intervention performed ( 1 point) / no intervention performed ( 0 point). If all the non-missing variables were equal to 0 and at least one was missing, the score was assigned a missing value.

For the category 'drugs prescribed in 1993', the preventive intervention was considered as performed only if psychotropic and hypotensive drugs were not prescribed. Regarding the prescription of drugs during hospitalization, a preventive intervention was considered as performed if either psychotropic or hypotensive drugs, or both, were reduced during hospitalization. If information regarding either type of drug was missing, the score was assigned a missing value.

\section{Statistical analysis}

A univariate description of preventive interventions and related scores was followed by exploratory bivariate analyses aimed at assessing associations between scores and potential determinant variables (age, gender, destination after discharge from hospital, comorbidity, cognitive functioning, and activities of daily living). Chi-square and Kruskal-Wallis tests were used. Finally, exploratory multivariate analyses were performed, to examine the relation between each potential determinant and preventive interventions (as separate dependent variables), in the presence of the other determinants. Logistic and linear regression analyses were performed, and conducted on "Intercooled Stata 4.0". Associations were considered statistically significant when $p$-values were $<0.05$ in bivariate and $<0.1$ in multivariate analyses.

\section{RESULTS}

The majority of the 163 patients were women $(\mathrm{N}=136,83 \%)$; the mean age was 81 (median 82, range 54-101). Forty-eight patients died during the 2 years following the fracture (29\%), 6 during hospitalization for acute care or in the rehabilitation clinic, and 30 in a nursing home. One patient was lost to follow-up, and 12 refused to participate in the follow-up examination. Among the 131 patients living in the community before the fracture, 49 (37\%) were placed in a nursing home up to 1993, definitively for most of them. In 1993, 31 patients were living in a nursing home, i.e., $27 \%$ of the survivors.

\section{Medical investigations}

Thirty medical examinations were performed in 20 patients (12\%). Cardiovascular check-ups were the most common (9), followed by investigations of cognitive (5) and metabolic problems (5), visual (4), 'other' (4) and neurological investigations (3). No specific investigations, or consultations for potential auditory, vestibular, cerebrovascular, cervical, motor or vitamin B12-related impairments were performed.

\section{Prescription of drugs}

Treatment modifications in 1991

Before hospital admission, $40 \%$ of the patients used sedatives, $10 \%$ antidepressants, and $44 \%$ hypotensives. Overall, about half of the patients with a hip fracture used at least one of these drugs. The prescription of these drugs was unchanged in most patients during hospitalization (Table 1). However, prescriptions of at least one drug in these two cate- 
Table 1 - Drugs increasing the risk of falling. Modifications of prescription during hospitalization in 1991: number and percent of patients $(N=163)$.

\begin{tabular}{lcccc}
\hline Modifications of prescription & Psychotropics & \multicolumn{2}{c}{ Hypotensives } \\
& $\mathrm{N}(\%)$ & $\mathrm{N}$ & $(\%)$ \\
\hline Reduced or interrupted (\%) & $10(6)^{\mathrm{a}}$ & 7 & $(4)^{\mathrm{b}}$ & 18 \\
Increased or introduced (\%) & $29(18)$ & $11)$ & $133^{\mathrm{d}}(82)$ & $(32)$ \\
No change (\%) & $119^{\mathrm{c}}(73)$ & 5 & $(3)$ \\
Missing (\%) & 5 & $(3)$ & \\
\hline
\end{tabular}

\footnotetext{
a Proportion of those using psychotropics on admission;

${ }^{b}$ Proportion of those using hypotensives on admission;

c $52 \%$ did not use psychotropics before hospital admission;

d $56 \%$ did not use hypotensives before hospital admission.
}

gories were globally reduced or stopped in only $16 \%$ of the patients, whereas an increased or new prescription was filled for $26 \%$ of them.

On admission, one patient was treated with calcium plus vitamin $\mathrm{D}$, another with calcium only, and 7 (5\%) with hormone replacement therapy. The association calcium plus vitamin $\mathrm{D}$ was prescribed for 2 patients during hospitalization, therefore only 4 among the 163 patients received calcium or vitamin $\mathrm{D}$, or calcium plus vitamin $\mathrm{D}$ at discharge.

\section{Drug treatment in 1993}

Sixty-nine percent of the patients used one or both of the two categories of drugs (psychotropics 58\%, hypotensives $37 \%$, and both $27 \%$ ), whereas only $17 \%$ did not use any of them (Table 2). This use increased between 1991 and 1993 in $20 \%$ of the patients, and diminished in $18 \%$ (psychotropics $7 \%$, hypotensives $11 \%$ ). In $1993,52 \%$ of the patients used sedatives, and $18 \%$ other psychotropics (e.g., antidepressants, neuroleptics).

Finally, the mean, and median total number of drugs used per day was 3 . Twenty percent of the patients were prescribed 0 to 2 drugs per day; $30 \%$, $2-3$; 24\%, 4-5; and 8\%, 6-9 (missing: 18\%).

\section{Counselling}

Among the patients alive in 1993, 55 (34\%) re- membered that they were given at least one recommendation, whereas $27(17 \%)$ indicated that they did not receive any (Table 3). The most frequent recommendation was to have a vision check-up (19\%), followed by counselling to practice physical exercise (12\%), and to control the feet (10\%).

\section{Environment modifications}

In 68 patients (42\%), at least one modification in the physical environment at the place of living was made in order to reduce the risk of falling, whereas no change was made for 37 patients (23\%) (Table 3 ). The most common change was the removal of objects that the patient could climb on (30\%), followed by modifications of floors (10\%), and rearrangements in the bathroom (9\%).

\section{Home assistance}

No information was obtained about assistance at home from 84 patients (death, refusal, no response at follow-up, or living in a nursing home). Thus, 79 patients (or families) answered; 67 (85\%) patients were receiving one or more types of professional assistance at home, and 12 (15\%) did not receive any. In 1993, the types of assistance were, in decreasing order: housekeeping, 30 (38\%); meals-on-wheels, 12 (15\%); general help provided by a Red Cross aide, 11 (14\%) or a nurse, 5 (6\%); and assistance through an alarm

Table 2 - Drugs increasing the risk of falling used in $1993(\mathrm{~N}=163)$.

\begin{tabular}{|c|c|c|c|c|c|c|}
\hline & yes & (\%) & no & $(\%)$ & missing * & (\%) \\
\hline Psychotropics & 95 & (58) & 43 & (26) & $25 *$ & (16) \\
\hline Hypotensives & 61 & (37) & 74 & $(45)$ & $28 *$ & (17) \\
\hline Both & 44 & (27) & 28 & (17) & & \\
\hline
\end{tabular}

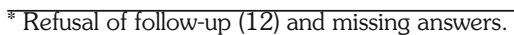


Table 3 - Counselling and modifications of environment $(N=163)$.

\begin{tabular}{|c|c|c|c|c|c|c|c|c|}
\hline$\overline{\text { COUNSELLING }}$ & yes & (\%) & no & $(\%)$ & unknown & $(\%)$ & missing $^{\mathrm{a}, \mathrm{b}}$ & $(\%)$ \\
\hline Check vision & 31 & (19) & 51 & (31) & 19 & (12) & 62 & (38) \\
\hline Check audition & 10 & (6) & 72 & (44) & 19 & (12) & 62 & (38) \\
\hline Check feet & 17 & (10) & 66 & (41) & 18 & (11) & 62 & (38) \\
\hline Improve nutrition & 15 & (9) & 69 & (42) & 17 & (10) & 62 & (38) \\
\hline Improve physical exercise & 20 & $(12)$ & 64 & (39) & 17 & (10) & 62 & (38) \\
\hline \multicolumn{9}{|l|}{ ENVIRONMENT } \\
\hline Increase lighting & 2 & (1) & 98 & $(60)$ & 4 & (2) & 59 & (36) \\
\hline Reduce bed height & 3 & (2) & 97 & (60) & 4 & (2) & 59 & (36) \\
\hline Place security bars & 9 & (6) & 92 & (56) & 4 & (2) & 58 & (36) \\
\hline Rearrange bathroom & 15 & (9) & 85 & (52) & 4 & $(2)$ & 59 & (36) \\
\hline Suppress objects to climb on & 49 & $(30)$ & 54 & (33) & 5 & (3) & 55 & (34) \\
\hline Modify floors & 16 & $(10)$ & 84 & $(52)$ & 4 & $(2)$ & 59 & (36) \\
\hline
\end{tabular}

a Counselling: missing values: 48 deceased, 12 refused to participate, and 2 missing answers.

${ }^{b}$ Environment: missing values: 34 deceased, 12 refused to participate, and 12 missing answers.

device (Secutel R) in two patients only. Between 1991 and 1993, 61 of these 79 patients received one or more types of help.

In addition to these 5 categories of preventive interventions, $32 \%$ of the patients had physiotherapy after hospitalization, and $47 \%$ did not. Among the patients who answered the question regarding the amount of time spent outdoors daily in 1993 (36\% missing), 52 spent more than 30 minutes, and 52 less.

The associations between categories of preventive interventions (according to the dichotomous score: preventive intervention performed or not), and determinants of their use are presented in Table 4. Only $p$-values are reported as a summary indication. Gender was not associated with the use of any of these preventive measures. The general trend of the bivariate associations indicated that the different preventive interventions and indicators examined were less often observed in the oldest patients, in those discharged to nursing home or dependent, as well as in patients with high comorbidity (3 or more pathologies) or an altered mental state. However, after multivariate adjustment including all the predictors, this trend was not confirmed. Only a few associations remained significant, indicating, as expected, that being older, living in a nursing home, and having an impaired mental status were independently associated with spending less time outdoors (Table 4). However, the models used in this analysis only weakly explained the variance of the dependent variables ( 6 to $22 \%$ ).

A post-hoc hypothesis was explored: 'Reducing the use of drugs which favor falls (psychotropics and hypotensives) during the hospitalization in 1991 predicts a less frequent use of these drugs in 1993'. The ration- ale was that the 'preventive measure' adopted in the hospital could influence the general practitioner who would then strive to reduce the risk of subsequent falls and fractures through prudent drug prescription. No significant association was found, and the hypothesis was rejectession

The main result of this study is that prevention of recurrent falls and fractures after a first hip fracture is not systematically performed in the surveyed area, neither in the hospital nor after discharge from hospital.

Medical investigations to find a manageable potential risk factor for future falls or osteoporosis were performed in only $12 \%$ of the patients during the acute hospital stay. Furthermore, this is certainly an upper limit, because most of these exams were probably not aimed at investigating reasons for falls or bone fragility. Examination of patients regarding cardiovascular problems or dementia, for instance, was probably justified by current cardiac problems or disorientation, and was not made with the aim of preventing future falls. On the other hand, some bedside examination (e.g., cervical functioning, examination of the locomotion apparatus) might have been performed without being reported in the medical record.

On entry to hospital, many patients were using drugs that raise the risk of falling, and the number of medications further increased during hospitalization. Patterns of prescription of drugs involving a risk of recurrent falls, during hospitalization in 1991 and in 1993, indicated that the existence of an increased risk of falling in these patients apparently was not a 
Table 4 - Associations between preventive interventions and determinants of their use (p-values as summary indicators of the associations).

\begin{tabular}{|c|c|c|c|c|c|c|}
\hline \multirow{2}{*}{ Interventions } & & \multicolumn{5}{|c|}{ Predictors } \\
\hline & & $\overline{\text { Age }}$ & Destination & Comorbidity & Mental state & Autonomy \\
\hline \multirow{2}{*}{$\begin{array}{l}\text { Medical } \\
\text { investigations }\end{array}$} & B: & 0.810 & 0.958 & 0.199 & 0.902 & 0.450 \\
\hline & M: & 0.598 & 0.919 & $0.037^{\prime \prime}$ & 0.267 & 0.732 \\
\hline \multirow{2}{*}{$\begin{array}{l}\text { Drugs in hospital } \\
\text { in } 1991\end{array}$} & B: & 0.782 & 0.193 & 0.429 & 0.103 & 0.996 \\
\hline & M: & 0.764 & 0.142 & 0.165 & 0.581 & 0.754 \\
\hline \multirow{2}{*}{$\begin{array}{l}\text { Drugs at home } \\
\text { in } 1993\end{array}$} & B: & $<0.007^{*}$ & 0.796 & 0.217 & $0.035^{*}$ & $0.010^{*}$ \\
\hline & M: & 0.374 & 0.592 & 0.414 & 0.184 & 0.158 \\
\hline \multirow{2}{*}{$\begin{array}{l}\text { Preventive } \\
\text { recommendations }\end{array}$} & B: & $0.016^{\dagger}$ & $0.103^{*}$ & 0.238 & 0.179 & 0.395 \\
\hline & M: & 0.418 & 0.084 & 0.615 & 0.224 & 0.884 \\
\hline \multirow{2}{*}{$\begin{array}{l}\text { Environment } \\
\text { modifications }\end{array}$} & B: & 0.751 & 0.453 & 0.054 & 0.899 & 0.274 \\
\hline & M: & 0.408 & 0.795 & 0.946 & 0.957 & 0.371 \\
\hline \multirow[t]{2}{*}{ Home assistance } & $\mathrm{B}:$ & 0.570 & 0.106 & 0.282 & 0.469 & 0.152 \\
\hline & M: & 1.000 & 0.923 & 0.635 & $* *$ & 䖮 \\
\hline \multirow[t]{2}{*}{ Total no. of drugs } & B: & $0.053^{*}$ & $0.036^{*}$ & $<0.005^{*}$ & $0.070^{*}$ & 0.179 \\
\hline & M: & 0.983 & 0.196 & $0.016^{\#}$ & 0.419 & 0.903 \\
\hline \multirow{4}{*}{$\begin{array}{l}\text { Physiotherapy } \\
\text { after discharge } \\
\text { Time spent outdoors } \\
\text { in } 1993\end{array}$} & $\mathrm{~B}:$ & $0.041^{*}$ & 0.280 & 0.571 & $0.101^{*}$ & 0.927 \\
\hline & M: & 0.532 & 0.755 & 0.874 & 0.167 & 0.256 \\
\hline & B: & $<0.001^{*}$ & $<0.001^{*}$ & 0.278 & $<0.001^{*}$ & $0.020^{*}$ \\
\hline & M: & $0.036 \%$ & 0.0468 & 0.853 & $0.039^{+\dagger}$ & 0.637 \\
\hline \multicolumn{7}{|c|}{$\begin{array}{l}\text { B: bivariate analysis; M: multivariate analysis } \\
\text { * The association shows that the preventive intervention was less frequent when health st } \\
\text { morbidity, impaired mental state, impaired ADLs). } \\
\text { † The association does not indicate any interpretable sense. } \\
\text { \& Advanced age was associated with very little time spent outdoors. } \\
\text { \$ Entering a nursing home after discharge was associated with less time spent outdoors. } \\
\text { II High comorbidity was associated with more investigations. } \\
\text { \# High comorbidity was associated with a larger use of drugs. } \\
\text { ** Every patient with more than } 2 \text { errors in SPMHQ received home assistance. } \\
\dagger \dagger \text { An impaired cognitive functioning was associated with less time spent outdoors. } \\
\text { * Every dependent patient living in the community received home assistance. }\end{array}$} \\
\hline
\end{tabular}

major determinant of drug prescription. However, this is in no way a judgment of the appropriateness of the indication for the treatment, which can be perfectly justified on other medical grounds, like hypertension or depression; in such cases, stopping, reducing or avoiding to introduce an effective treatment could be more deleterious than beneficial for the patient's health. For instance, the increase in the use of hypotensive drugs might have been based on observations made during hospitalization, and the initial rise in the use of sleeping pills might have been due to the unusual environment, the trauma, and the surgery. The latter prescription, however, should have been adapted thereafter as well as on discharge from hospital. In general, an indication for drugs that increase the risk of falling should be particularly carefully evaluated in patients admitted to hospital for hip fracture.

The very low prescription rate of vitamin $\mathrm{D}$ or calcium supplements before and during hospitaliza- tion indicates that neither general practitioners nor hospital physicians were used to prescribing these treatments in 1991. Since that time, several studies have indicated that the potential benefits of vitamin $\mathrm{D}$ or calcium supplements can slow down osteoporosis, and reduce the number of fractures, even if the treatment is initiated late (38-40). The small number of women receiving hormonal replacement therapy in 1991 can be explained by the very high median age of this population. Indeed, the benefit of beginning hormone replacement therapy in women over 70 years of age is uncertain (7), and its risks and side effects are dissuasive (49). This survey did not allow a specific evaluation of the use of calcium, vitamin $\mathrm{D}$, and hormone replacement therapy in 1993, and this constitutes one of its limitations. There is, however, some indirect information indicating that pharmacologic prevention of osteoporosis has not increased much in the following years. For instance, data from a 1997 population survey, including 13 
000 people from all of Switzerland, showed that $10 \%$ and $6 \%$ of women aged 35 and over and 65 and over, respectively, used hormone replacement therapy. A daily use of 4 different drugs, whatever they are, increases the risk of falling $(7,20)$. In this study, the median was 3 drugs per day, hence a comprehensive evaluation of drug prescription, with the aim of reducing total prescription, would be of possible benefit.

The majority of the patients were given at least one preventive recommendation. However, answers to these questions were strongly dependent on the patients' memory. Moreover, it is unknown whether all these recommendations were given with the explicit purpose of preventing recurrent falls and fractures, because numerous other medical reasons could have justified most of them.

Environmental modifications represent preventive strategies clearly aimed at reducing the risk of falling. This type of prevention, if affordable, is probably feasible, because it needs only one single intervention, and no active collaboration from the patient. Results were considered good, since about half of the patients who answered received this type of prevention. Assistance at home was frequent; it must be interpreted as indicating the needs of the patient in relation to the lack of self-sufficiency, rather than a preventive measure.

This study has several limitations. Response rates were frequently low. The accuracy of patients' answers is uncertain, because many were derived from patients' recall. In addition, some patients presented cognitive impairments. The list of preventive interventions examined was not exhaustive. In fact, some preventive interventions were incompletely, or not at all investigated in this study, such as physical training $(26,32,34)$, use of hip pads (50), consumption of dairy products (44-46), use of other drugs affecting bone metabolism $(32,33,42)$, and use of calcium, vitamin $\mathrm{D}$ and hormone replacement therapy in 1993. Analysis of the use of drugs that increase the risk of falling is limited, as the appropriateness of their indication was unknown. Finally, this study was conducted several years ago, and the use of preventive interventions in hip fracture patients might have increased since then.

Despite these limitations, we explored the associations between preventive interventions and predictive factors. Globally, the main result of the bivariate analyses is that a poor general status, indicated by a very old age, high comorbidity, a poor mental status, and a lack of autonomy, seems to be an important limitation to the application of preventive interventions; however, multivariate analysis does not support this hypothesis. One explanation might reside in the small number of preventive interventions used, that translated into a low power of this analysis.

Patients in poor general conditions are also those at highest risk for recurrent falls and fractures. They should, therefore, benefit from customized preventive interventions, which was not apparent in the studied group of patients. This lack of preventive interventions in patients who could benefit from them is mostly due to the requirement of an active participation on the part of the patients. Indeed, preventive interventions not requiring patient participation (e.g., environment modification) were generally used more often than those requiring active collaboration.

It seems that two main types of interventions should be applied to improve the prevention of recurrent falls and fractures after a first hip fracture. First, preventive activities which do not need the active participation of the patients, and are then more easily applicable should be favored, such as environmental modifications and assistance at home. Secondly, a comprehensive geriatric assessment should be performed systematically in patients who have been hospitalized for a hip fracture, in order to reveal modifiable pathologies raising the risk of recurrent falls, adapt medication according to priorities and also the risk of falling and osteoporosis, and improve physical abilities following appropriate counselling $(51,52)$ to the patient and relatives. Although a comprehensive geriatric assessment can be performed in the rehabilitation center, or by the general practitioner, it seems important to conduct it in the hospital as it may lead to early interventions, and allow informed decision-making for patient destination at discharge. Actually, this study shows that this opportunity was often missed in 1991. Therefore, it is necessary to promote effective preventive interventions to reduce the recurrence of falls and fractures in patients with a first hip fracture. Examining the effectiveness of those interventions in field studies, and investigating the barriers to the use of preventive interventions in patients, especially the frail elderly who have sustained a fracture of the proximal femur, are key themes for future research and development projects.

\section{ACKNOWLEDGEMENTS}

This study was supported by the Swiss National Science Foundation (grants 32-28626.90 and 83.517.0.87) and by the 'Fondation du 450ème anniversaire de l'Université de Lausanne'.

\section{REFERENCES}

1. Jéquier V., Burnand B., Vader J.P., Paccaud F.: Hip fracture 
incidence in the canton of Vaud, Switzerland, 1986-1991. Osteoporos. Int. 5: 191-195, 1995.

2. Maggi S., Kelsey J.L., Litvak J., Heyse S.P.: Incidence of hip fractures in the elderly: a cross-national analysis. Osteoporos. Int. 1: 232-241, 1991.

3. Weiss N.S., Liff J.M., Ure C.L., Ballard J.H., Abbott G.H., Daling J.R..: Mortality in women following hip fracture. $J$. Chronic Dis. 36: 879-882, 1983

4. Miller C.W.: Survival and ambulation following hip fracture. J. Bone Joint Surg. Am. 60: 930-934, 1978.

5. Mossey J.M., Mutran E., Knott K., Craik R.: Determinants of recovery 12 months after hip fracture: the importance of psychosocial factors. Am. J. Public Health 79: 279-286, 1989.

6. Cummings S.R., Kelsey J.L., Nevitt M.C., O'Dowd K.J.: Epidemiology of osteoporosis and osteoporotic fractures. Epidemiol. Rev. 7: 178-208, 1985.

7. Rubin F.H.: Falls: the potential for preventing disability in the elderly. Society for General Internal Medicine, 15th Workshop, Washington, D.C., 1992.

8. Boston D.A.: Bilateral fractures of the femoral neck. Injury 14: 207, 1983

9. Tinetti M.E.: Prevention of falls and fall injuries in elderly persons: a research agenda. Prev. Med. 23: 756-762, 1994.

10. Schroder H.M., Petersen K.K., Erlandsen M.: Occurrence and incidence of the second hip fracture. Clin. Orthop. 289: 166-169, 1993

11. Chiu K.Y., Pun W.K., Luk K.D., Chow S.P.: Sequential fractures of both hip in elderly patients: a prospective study. $J$. Trauma 32: 584-587, 1992.

12. Dretakis E., Kritsikis N., Economou K., Christodoulou N.: Bilateral non-contemporary fractures of the proximal femur. Acta Orthop. Scand. 52: 227-229, 1981.

13. Finsen V.: The second hip fracture: an epidemiologic study. Acta Orthop. Scand. 57: 431-433, 1986.

14. Nevitt M.C., Cummings S.R.: Type of fall and risk of hip and wrist fractures: the study of osteoporotic fractures. J. Am. Geriatr. Soc. 41: 1226-1234, 1993.

15. Prudham D., Evans J.G.: Factors associated with falls in the elderly: a community study. Age Ageing 10: 141-146, 1981.

16. Tinetti M.E.: Factors associated with serious injury during falls by ambulatory nursing home residents. J. Am. Geriatr. Soc. 35: 644-648, 1987.

17. Sattin R.W., Lambert Huber D.A., DeVito C.A., Rodriguez J.G., Ros A., Bacchelli S., Stevens J.A., Waxweiler R.J.: The incidence of fall injury events among the elderly in a defined population. Am. J. Epidemiol. 13: 1028-1037, 1990.

18. The prevention of falls in later life: a report of the Kellogg International Work Group on the Prevention of Falls by the Elderly. Dan. Med. Bull. 34 (Suppl. 4): 1-24, 1987.

19. Tinetti M.E., Baker D.I., Garrett P.A., Gottschalk M., Koch M.L., Horwitz R.I.: Yale FICSIT: risk factor abatement strategy for fall prevention. J. Am. Geriatr. Soc. 41: 315-320, 1993.

20. Tinetti M.E., Baker D.I., McAvay G., Claus E.B., Garrett P., Gottschalk M., Koch M.L., Trainor K., Horwitz R.I.: A multifactorial intervention to reduce the risk of falling among elderly people living in the community. N. Engl. J. Med. 331: 821-827, 1994.
21. Cumming R.G., Miller J.P., Kelsey J.L., Davis P., Arfken C.L., Birge S.J., Peck W.A.: Medications and multiple falls in elderly people: the St Louis OASIS Study. Age Ageing 20: 455-461, 1991.

22. Malmivaara A., Heliovaara M., Knekt P., Reunanen A., Aromaa A.: Risk factors for injurious falls leading to hospitalisation or death in a cohort of 19500 adults. Am. J. Epidemiol. 138: 384-394, 1993.

23. Sorock G.S., Shimkin E.E.: Benzodiazepine sedatives and the risk of falling in a community-dwelling elderly cohort. Arch. Intern. Med. 148: 2441-2444, 1988.

24. Lucht $U$.: A prospective study of accidental falls and resulting injuries in the home among elderly people. Acta Sociomed. Scand. 3: 105-120, 1971.

25. Tinetti M.E., Speechley M., Ginter S.F.: Risk factors for falls among elderly persons living in the community. N. Engl. J. Med. 319: 1701-1707, 1988.

26. Paganini-Hill A., Chao A., Ross R.K., Henderson B.E.: Exercise and other factors in the prevention of hip fracture: the leisure world study. Epidemiology 2: 16-25, 1991.

27. Sauvage L.R. Jr, Myklebust B.M., Crow-Pan J., Novak S. Millington P., Hoffman M.D., Hartz A.J., Rudman D.: A clinical trial of strengthening and aerobic exercise to improve gait and balance in elderly male nursing home residents. Am. J. Phys. Med. Rehabil. 71: 333-342, 1992.

28. Loew F.: The elderly can avoid falls. World Health 46: 1011, 1993.

29. Dunne R.G., Bergman A.B., Rogers L.W., Inglin B., Rivara F.P.: Elderly persons' attitudes towards footwear: a factor in preventing falls. Public Health Rep. 108: 245-248, 1993.

30. Jantti P.O., Pyykko V.I., Hervonen A.L.: Falls among elderly nursing home residents. Public Health 107: 89-96, 1993.

31. Grisso J.A., Kelsey J.L., Strom B.L., Chiu G.Y., Maislin G., O'Brien L.A., Hoffman S., Kaplan F.: Risk factors for falls as a cause of hip fracture in women: the Northeast Hip Fracture Study Group. N. Engl. J. Med. 324: 1326-1331, 1991.

32. Law M.R., Wald N.J., Meade T.W.: Strategies for prevention of osteoporosis and hip fracture. BMJ 303: 453-459, 1991.

33. Lindsay R.: Prevention of osteoporosis. Prev. Med. 23: 722726, 1994.

34. Silver J.J., Einhorn T.A.: Osteoporosis and aging: current update. Clin. Orthop. 316: 10-20, 1995.

35. Christiansen C.: Prevention and treatment of osteoporosis with hormone replacement therapy. Int. J. Fertil. 38 (Suppl. 1): 45-54, 1993.

36. Gorsky R.D., Koplan J.P., Peterson H.B., Thacker S.B.: Relative risks and benefits of long-term estrogen replacement therapy: a decision analysis. Obstet. Gynecol. 83: 161-166, 1994

37. Hillard T.C., Whitcroft S.J., Marsh M.S., Ellerington M.C., Lees B., Whitehead M.I., Stevenson J.: Long-term effects of transdermal and oral hormone replacement therapy on postmenopausal bone loss. Osteoporos. Int. 4: 341-348, 1994.

38. Chapuy M.C., Arlot M.E., Delmas P.D., Meunier P.J.: Effect of calcium and cholecalciferol treatment for three years on hip fractures in elderly women. BMJ 308: 1081-1082, 1994.

39. Chapuy M.C, Arlot M.E., Duboeuf F., Brun J., Crouzet B., Arnaud S., Delmas P.D., Meunier P.J.: Vitamin D3 and calcium to prevent hip fractures in elderly women. N. Engl. J. 
Med. 327: 1637-1642, 1992.

40. Chevalley T., Rizzoli R., Nydegger V., Slosman D., Rapin C.H., Michel J.P., Vasey H., Bonjour J.P.: Effects of calcium supplements on femoral bone mineral density and vertebral fracture rate in vitamin-D-replete elderly patients. Osteoporos. Int. 4: 245-252, 1994.

41. Black D.M., Cummings S.R., Karpf D.B., Cauley J.A., Thompson D.E., Nevitt M.C., Bauer D.C., Genant H.K., Haskell W.L., Marcus R., Ott S.M., Torner J.C., Quandt S.A., Reiss T.F., Ensrud K.E.: Randomised trial of effect of alendronate on risk of fracture in women with existing vertebral fractures : Fracture Intervention Trial Research Group. Lancet 348: 1535-1541, 1996.

42. Levin R.M.: The prevention of osteoporosis. Hosp. Pract. 26: 77-80, 83-86, 91-94, 1991.

43. Lloyd T., Andon M.B., Rollings N., Martel J.K., Landis J.R., Demers L.M.: Calcium supplementation and bone mineral density in adolescent girls. JAMA 270: 841-844, 1993.

44. Murphy S., Khaw K.T., May H., Compston J.E.: Milk con- sumption and bone mineral density in middle aged and elderly women. BMJ 308: 939-941, 1994.

45. Soroko S., Holbrook T.L., Edelstein S., Barrett-Connor E.: Lifetime milk consumption and bone mineral density in older women. Am. J. Public Health 84: 1319-1322, 1994.

46. Birge S.J.: Osteoporosis and hip fracture. Clin. Geriatr. Med. 9: 69-86, 1993.

47. Välimäki M.J., Karkkainen M., Lamberg-Allardt C., Laitinen K., Alhava E., Heikkinen J., Impivaara O., Makela P., Palmgren J., Seppanen R., Vuori I.: Exercises, smoking, and calcium intake during adolescence and early adulthood as determinants of peak bone mass: Cardiovascular Risk in Young Finns Study Group. BMJ 309: 230-235, 1994.

48. Pfeiffer E.: A short portable mental status questionnaire for the assessment of organic brain deficit in elderly patients. $J$. Am. Geriatr. Soc. 23: 433-441, 1975.

49. Kanis J.A., Johnell O., Gullberg B., Allander E., Dilsen G., Gennari C., Lopes Vaz A.A., Lyritis G.P., Mazzuoli G., Miravet L., Passeri M., Perez Cano R., Rapado A., Ribot C.: Evidence for efficacy of drugs affecting bone metabolism in preventing hip fracture. BMJ 305: 1124-1128, 1992. 